\title{
El rol del mármol en la configuración del paisaje epigráfico de Tarraco
}

\section{The Role of Marble in the Epigraphic Landscape of Tarraco}

\author{
Julio C. Ruız \\ Institut Català d'Arqueologia Clàssica. Tarragona \\ jcruiz@icac.cat \\ http://orcid.org/0000-0002-6562-9040
}

Fecha de recepción: 18-01-2020

Fecha de aceptación: 25-03-2020

\section{RESUMEN}

En este artículo realizamos un estudio de los programas epigráficos de los edificios públicos en Tarraco durante el periodo altoimperial, centrándonos en el soporte y concretamente en los materiales lapídeos en que están realizadas las inscripciones. Nuestro objetivo es valorar el papel que ejerció el mármol lunense como materia prima en contraposición a otras rocas ornamentales, tanto de carácter local como importado. Como resultado, ponemos de manifiesto que este material sirve como indicador socioeconómico, puesto que fue utilizado para la elaboración de las inscripciones relacionadas con los individuos más privilegiados de los espacios y edificios públicos de mayor importancia en la capital de la provincia Hispania citerior.

Palabras clave: epigrafía latina, mármol blanco, Luni-Carrara, foro, edificios de espectáculos Topónimos: Tarraco (conventus Tarraconensis, Hispania citerior)

Periodo: periodo altoimperial romano

\section{ABSTRACT}

This article aims to study the epigraphic programs of public buildings in Tarraco during the Early Roman period. It focuses on epigraphic support and, in particular, stones on which the inscriptions are made. The goal is to assess the role that Luni-Carrara marble played as raw material as opposed to other ornamental stones, both local and imported. As a result, this material is shown to have served as a socio-economic indicator, since it was used for the elaboration of inscriptions associated with the most privileged individuals in the most important public spaces and buildings in the capital of the province Hispania citerior.

Key words: Latin Epigraphy, white marble, Luni-Carrara, forum, spectacle buildings

Toponyms: Tarraco (conventus Tarraconensis, Hispania citerior)

Period: Early Roman period 


\section{INTRODUCCIÓN}

En los últimos años venimos desarrollando una línea de investigación dedicada al uso y difusión de rocas ornamentales y otras piedras, locales y foráneas, a través del estudio de materiales arqueológicos procedentes de Tarraco (Gorostidi Pi y Ruiz, 2017a; Ruiz, 2017; Ruiz, 2018; Ruiz, 2019a; Ruiz et alii, en prensa) ${ }^{1}$. Se trata de una línea de largo recorrido por lo que a conjuntos epigráficos hispanorromanos se refiere, aunque en la actualidad la caracterización sistemática de las materias primas utilizadas para la producción de soportes epigráficos no es una práctica metodológica completamente consolidada. Queremos destacar a este respecto los casos del travertino rojo de Mula en la región murciana (Soler Huertas, 2005), los marmora de Lusitania (Andreu Pintado, 2012) y de Clunia (Rodríguez Ceballos y Salido, 2014). De mayor interés resulta un trabajo recientemente publicado, donde han sido recopilados los soportes hermaicos de Hispania, poniendo de manifiesto el rol desempeñado por materiales lapídeos de origen hispanorromano (Galán Palomares, 2019). Por lo que respecta a Tarraco, además de nuestras contribuciones que ya hemos mencionado anteriormente, mencionaremos entre otros el trabajo dedicado a la piedra de Alcover como soporte epigráfico (Gorostidi Pi et alii, 2018).

\section{EL MÁRMOL COMO SOPORTE EPIGRÁFICO EN LOS EDIFICIOS PÚBLICOS DE TARRACO}

Entre todas las rocas de mayor valor ornamental y funcional destaca el mármol lunense, como material lapídeo importado a mayor escala no sólo en Tarragona, sino en todo el Mediterráneo occidental (Pensabene, 2012), a juzgar por el abundante número de elementos arquitectónicos, epigráficos y escultóricos conservados. En Tarraco, dos de sus aspectos más destacables son su temprana introducción (Ruiz, 2018) y el simbolismo que se deduce de su empleo en la epigrafía oficial, con unas destinaciones muy específicas (Gorostidi Pi y Ruiz, 2017a: 328-331; Ruiz, 2017: 45-47).

En la zona nororiental de la península ibérica no hay zonas extractivas de mármoles explotadas en época romana (Gutiérrez García-Moreno, 2009), por lo que su presencia es indicio de la importación de material. Aun así, Tarraco fue una de las urbes hispanorromanas más "marmorizadas" gracias a la adquisición de materiales lapídeos foráneos, destacando los mármoles blancos y particularmente de los procedentes de Luni-Carrara (Gutiérrez García-Moreno y Rodà de Llanza, 2012). Las rocas ornamentales de circulación global en la cuenca mediterránea en la época imperial comenzaron a llegar regularmente a esta zona a partir del periodo augusteo (Gutiérrez García-Moreno y Rodà de Llanza, 2012: 294), comenzando por los mármoles blancos (Ruiz, 2018). El florecimiento económico de las ciudades y el auge de sus élites locales, entre otras razones, dieron lugar a una creciente demanda de material destinado a programas ornamentales y monumentales acordes con el nuevo orden político y socioeconómico.

Sin embargo, en Tarraco los primeros testimonios del empleo de mármoles blancos, documentado mediante esculturas y objetos suntuarios, se remontan incluso al periodo

1 Este artículo se ha realizado dentro del proyecto HAR2015-65319-P (MINECO/FEDER, UE). Se enmarca asimismo en la realización de mi tesis doctoral (FPU2016/00675), a cuyos directores Joaquín Ruiz de Arbulo y Diana Gorostidi agradezco su inestimable ayuda. Todas las imágenes de las inscripciones pertenecen al archivo fotográfico del autor y han sido realizadas con el permiso de los museos correspondientes. Quiero expresar mi agradecimiento por las facilidades concedidas a Sofía Mata, directora del Museo Diocesano de Tarragona (MDT); Mònica Borrell (directora), Gemma Jové, Montserrat Perramon y Josep Anton Remolà del Museu Nacional Arqueològic de Tarragona (MNAT); Lluís Balart (director), Jordi Parral y Cristòfor Salom del Museu d'Història de Tarragona. Por último, también quiero agradecer a los evaluadores anónimos sus comentarios y sugerencias, que han contribuido a enriquecer el contenido de este artículo. 
inmediatamente anterior al reinado de Augusto (Ruiz, 2018) Por lo que respecta a la epigrafía (Ruiz, 2017: 45-48), a comienzos de la época imperial tan sólo es seguro el uso del mármol blanco en una mensa ponderaria (CIL II/2/14, 1205), en tanto que para la producción epigráfica de este mismo periodo existe un predominio masivo de las rocas locales (Gorostidi Pi y López Vilar, 2015; Ruiz, 2017: 37-45, figuras 2-5). Durante el periodo julio-claudio se datan algunas placas con restos de inscripciones, halladas en el foro local, que han sido atribuidas a homenajes a miembros de la domus Augusta (CIL II/2/14, 886887, 889/90, 1943; Ruiz, 2017: 47-48; Ruiz, 2019b: 314, figura 13b-d). Con este mismo uso se mantuvo a partir del periodo flavio, como testimonian algunos ejemplares mejor conservados. Del foro local proceden una placa de gran anchura dedicada a Tito en el año 72 (CIL II/14, 897) y otra placa para un pedestal de Lucio Vero divinizado en bardiglio (CIL $\left.\|^{2} / 14,910\right)$. Dos fragmentos de una misma placa conservan una posible mención a Caracalla (CIL II/14, 919) y es de suponer, aunque fue recuperada en la necrópolis paleocristiana (Aranda y Ruiz 2019: 94, figura 4), que un placado destinado quizá a una estatua colosal del mismo emperador estuviese ubicado originalmente en el mismo foro (CIL II/14, 920). En el cercano teatro fue hallado un ara de magnífica ejecución con la inscripción numini August(i/-orum), para la que Alföldy ha defendido reiteradamente una datación en el periodo augusteo, si bien no puede descartarse una cronología flavia, que parece verse apoyada en sus particularidades paleográficas $\left(C / L I^{2} / 14,851\right)$. Del mismo edificio teatral proceden dos inscripciones monumentales, en ambos casos inscritas en placas muy fragmentadas, destinadas a sendos pedestales estatuarios: la primera dedicada a Septimio Severo (CIL $I^{2} / 14$, 914) (Figura 1) y la segunda probablemente a Caracalla $\left(C / L I^{2} / 14,918\right)$.

Figura 1. MNAT, reg. T.TE.77. Dos fragmentos de una placa con inscripción honorífica dedicada a Septimio Severo, procedente del teatro

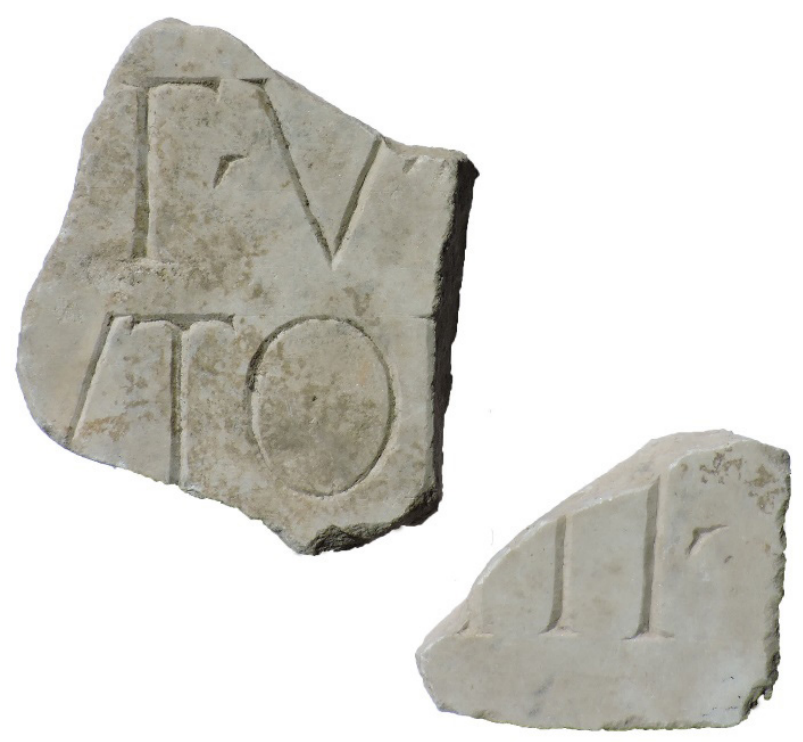

Fuente: $C I L I^{2} / 14,914$

Sin embargo, precisamente a partir de la época vespasianea en el paisaje urbano de Tarraco destaca la parte superior de la ciudad, donde se construyó un complejo monumental de dimensiones gigantescas (Mar Medina et alii, 2015: 67-211; Pensabene y Domingo Magaña, 2019) (Figura 2), relacionado con la reforma del culto imperial en este periodo 
y el proceso de municipalización extendido a toda Hispania (Andreu Pintado, 2004a: 39; Andreu Pintado, 2004b: 50-51). Los edificios estaban distribuidos en tres terrazas: la superior albergaba el templo de Augusto rodeado por un pórtico (Macias i Solé et alii, 2014a; Pensabene y Domingo Magaña, 2019: 73-86), la intermedia la "plaza de representación" (Díaz García y Teixell, 2014; Pensabene y Domingo Magaña, 2019: 86-93) y en la inferior se situaba el circo (Miró i Alaix, 2017). La construcción de este complejo también implicó un cambio radical en la elección de los soportes epigráficos y las materias primas lapídeas asociadas a la transformación del nuevo espacio público, conformando así una imagen unitaria con respecto a las estructuras arquitectónicas (Gorostidi Pi y Ruiz, 2017a). El programa de monumentalización supuso un estímulo determinante en el incremento de la epigrafía honorífica, expuesta principalmente en las terrazas superior e intermedia. En esta última se fueron colocando las estatuas de los miembros más destacados de la élite provincial, en especial los sumos sacerdotes del culto imperial (Alföldy, 1973; Fishwick, 2002: 73-137; Ortiz de Urbina, 2006: 49-69). Sus pedestales, realizados en las calizas ornamentales del entorno de Tarragona (Àlvarez Pérez et alii, 2009; Gutiérrez GarcíaMoreno, 2009: 208-226) y compuestos por tres piezas trabajadas por separado (Alföldy, 2012a: 437-444; Gorostidi Pi, 2017: 169-172, figura 1), condicionaron la imagen oficial del ámbito de Tarraco (Gorostidi Pi y Ruiz, 2017a: 331-335), que, a su vez, ejerció como modelo para las capitales conventuales de Hispania citerior y de otras muchas ciudades de la provincia (Alföldy, 1979: passim = Gorostidi Pi (ed.), 2017: 52-142 (G. Alföldy); Gorostidi $\mathrm{Pi}, 2017$ : 172-184).

Uno de los fenómenos con un mayor impacto en la configuración del renovado espacio público fue la llegada de volúmenes ingentes de mármol lunense, importado en bruto, para ser trabajado en la propia ciudad. Así lo han puesto de relieve los trabajos sobre los elementos arquitectónicos del templo al Divus Augustus y su temenos (Mar Medina y Pensabene, 2009: 374-380; Pensabene y Mar Medina, 2010; Pensabene y Domingo Magaña, 2019: passim; Ruiz, en prensa). El rol preponderante del mármol de Luni-Carrara no se limitó a los programas monumentales y decorativos, sino que además desplazó a los restantes materiales lapídeos en la producción de los nuevos soportes epigráficos, utilizados para honrar a los individuos más privilegiados y al mismo tiempo embellecer las estructuras arquitectónicas mediante inscripciones edilicias (Gorostidi Pi y Ruiz, 2017a: 330-331). 
Figura 2. Planimetría de la acrópolis de Tarraco a partir de época flavia

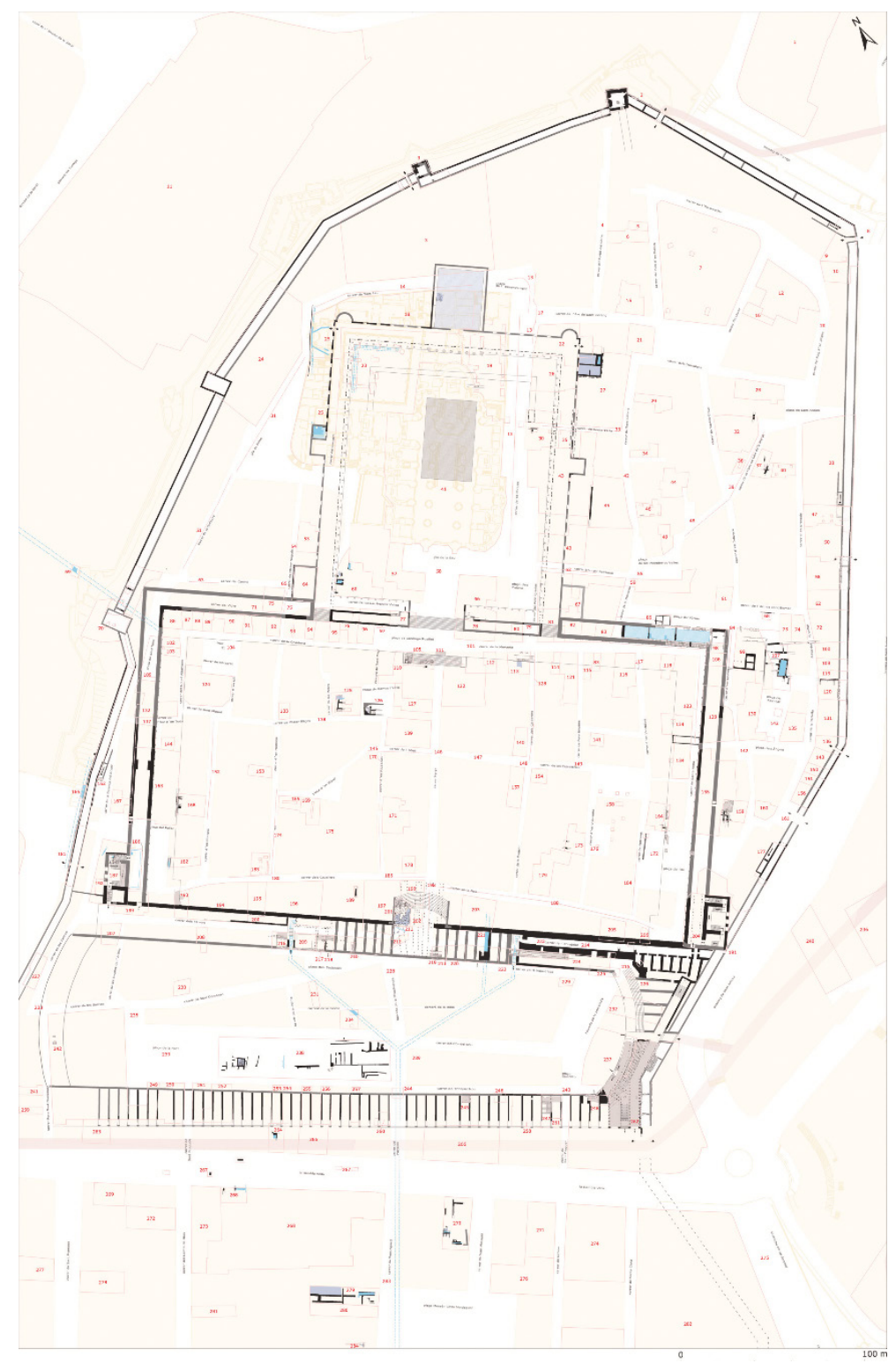

Fuente: Macias et al. (dirs.), 2007: lámina A1. 
Figura 3. MDT, n. ${ }^{\circ}$ inv. 5387. Fragmento de placa con inscripción a un miembro de la dinastía flavia, procedente del área del templo de Augusto

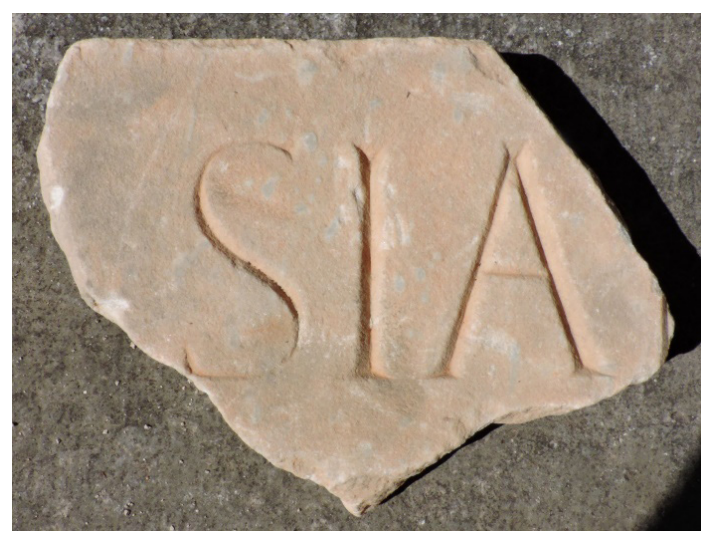

Fuente: $C I L I^{2} / 14,895$

Figura 4. MDT, n. ${ }^{\circ}$ inv. 242 A. Fragmento de placa con inscripción edilicia dedicada por un miembro de la dinastía flavia, procedente del área del templo de Augusto

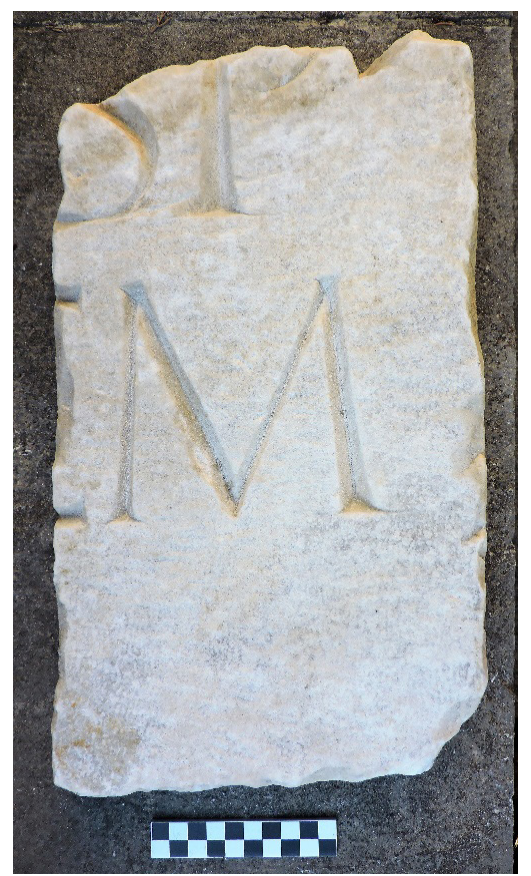

Fuente: $C I L I^{2} / 14,899$

Así lo documentan las placas con inscripciones honoríficas, dos de ellas dedicadas aparentemente a miembros indeterminados de la dinastía Flavia, que conservan restos del nombre de Vespasiano (CIL II²/14, 895 y 896) ${ }^{2}$ (Figura 3). Una tercera placa monumental fue recuperada durante las excavaciones en el área de la Catedral y contiene los restos de la inscripción honorífica de un personaje ignoto que ostentó presuntamente el cargo

2 La primera de ellas salió a la luz en el interior del espacio que ocupó el temenos del templo de Augusto, en tanto que la segunda apareció en el casco antiguo de la ciudad, asociada a otros materiales en claro contexto secundario desplazados desde el área del mismo templo (Fortuny Mendo y Ruiz, en prensa). 
de [curator te]mpli Di[vi Augusti], pudiendo fecharse en época flavia (Peña Jurado et alii, 2015). Contemporáneas son dos inscripciones monumentales edilicias, que corresponden a epígrafes de grandes dimensiones, compuestas por varias lastras: la primera, procedente del área del templo de Augusto, contiene parte de la titulatura de Tito o Domiciano seguida de la presunta mención de una [aed]es en acusativo (CIL II/2/14, 899) (Figura 4); la segunda, en varios fragmentos, procede del circo (CIL II/14, 898a-b, 900, 1913; Ruiz et al., en prensa), y con seguridad mencionaba a Domiciano y probablemente un magistrado que ejerció, entre otros, el cargo de flamen provincial (Gorostidi Pi y Ruiz, 2017b) (Figura 5). Esta última tiene un paralelismo en el gran placado, también en mármol lunense, procedente del anfiteatro (sobre este edificio: Macias i Solé et alii, 2014b; Mar Medina et alii, 2015: 213-237), que responde a una praxis epigráfica similar (CIL II/14, 1109; Alföldy, 2012b: 14-20) (Figura 6). Contiene la mención in extenso del cargo del flamen provincial, lo que ha llevado a pensar que el edificio de espectáculos fue financiado por, al menos, un sumo sacerdote de la provincia. El edificio se ha datado en época trajaneo-adrianea por lo que se supone para el epígrafe una datación similar.

Figura 5. MNAT, sigla arq. CTV-12-102/85-A-102 y TTV-13-221-14. Fragmentos de una inscripción edilicia con mención a Domiciano y un flamen provincial, procedente del circo
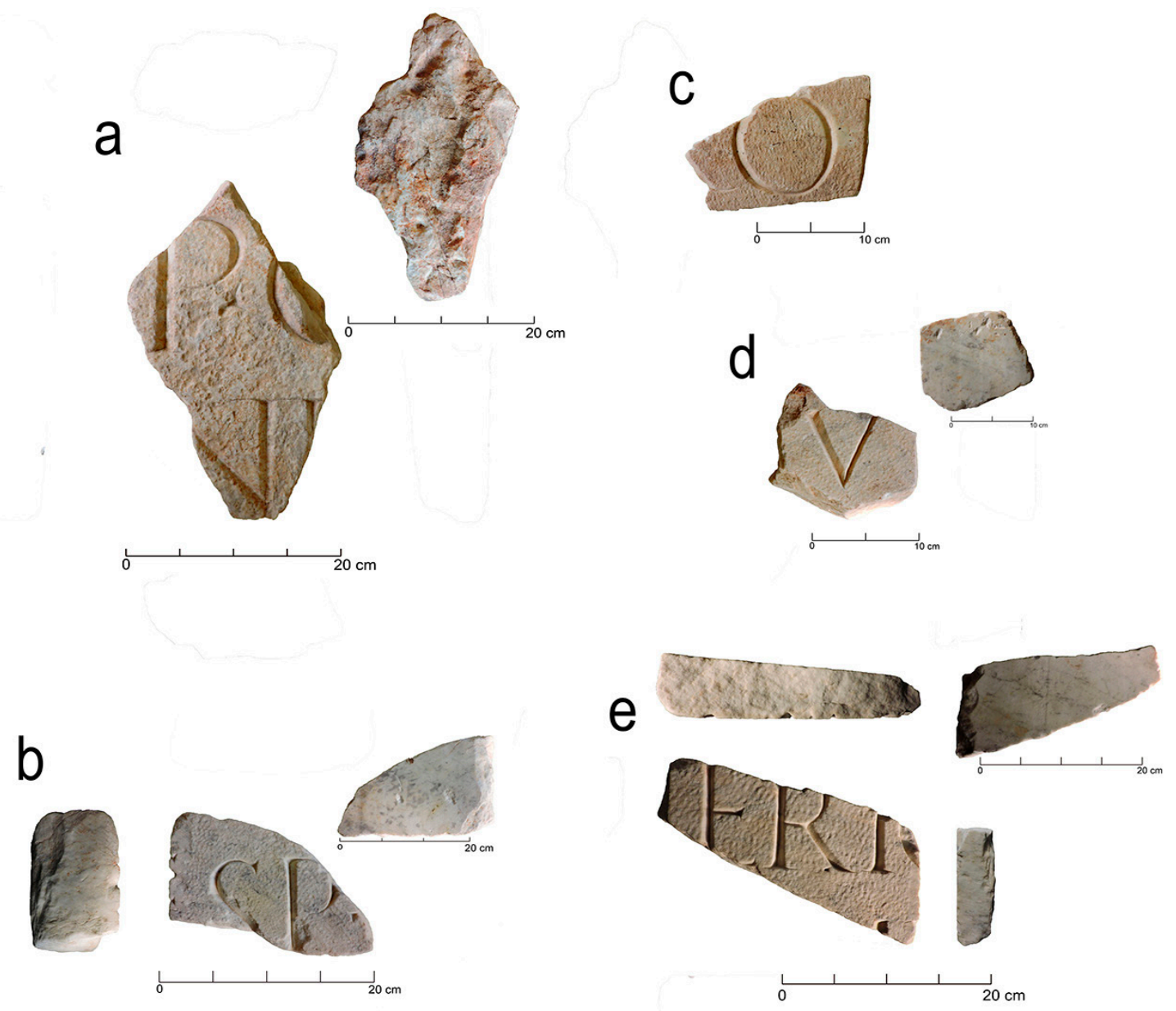

Fuente: CIL II²/14, 898, 900, 1913; Gorostidi y Ruiz 2017b 
Figura 6. MNAT, n. ${ }^{\circ}$ inv. 45054. Lastra con mención del cargo de flamen provincial, procedente del anfiteatro

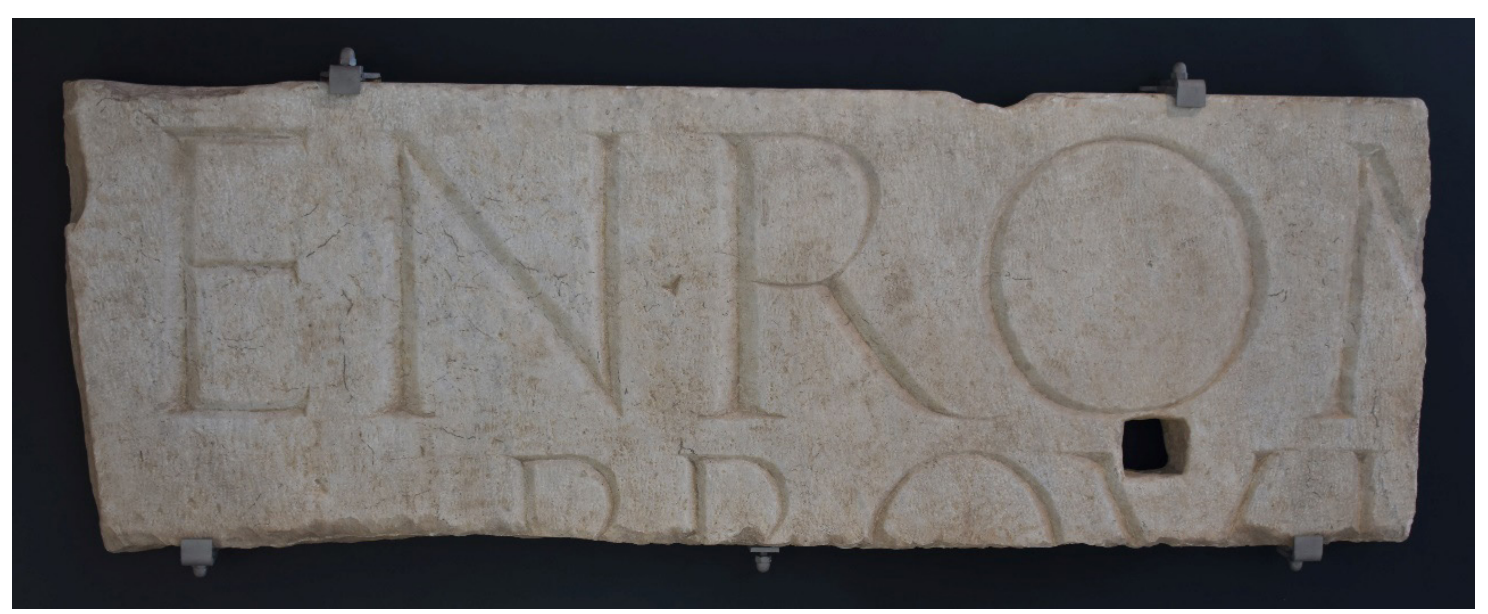

Fuente: CIL II²/14, 1109

La cesura con respecto a la epigrafía oficial de épocas anteriores se hace especialmente patente al confrontar los materiales utilizados en época julio-claudia para los mismos usos (Gorostidi Pi y López Vilar, 2015. Ruiz, 2017). Entre las inscripciones edilicias de aquel periodo (CIL II2/14, 874-876, 893) no se conserva ninguna en mármol u otro material importado, estando realizadas todas ellas en biocalcarenitas (Ruiz, 2017: 39-40, fig. 3). En cuanto a la epigrafía honorífica, como ya hemos mencionado, si bien se constatan algunos ejemplos en mármol, en la primera mitad del siglo I d.C. predominan los marmora de color importados de diversas zonas del Mediterráneo, empleados para placas fijadas a la cara anterior de pedestales dedicados a miembros de la familia imperial (Ruiz, 2017: 48-49; Ruiz, 2019b: 311-315, figs. 11-13). Entre estas rocas se hallan el africano de Teos (CIL $\left.I^{2} / 14,882-884\right)$, el giallo antico de Chemtou (CIL II $\left.2 / 14,885\right)$ y el pavonazzetto de Afyon (CIL II2/14, 957; cf. CIL II2/14, 887).

Por lo tanto, la irrupción masiva del mármol blanco también se deduce de las inscripciones de mayor significado político-ideológico, particularmente de las procedentes del foro provincial, desplazando al resto de materiales lapídeos de importación utilizados preferentemente como soporte epigráfico de prestigio. La elaboración de todas estas inscripciones debió requerir un cierto volumen de material, probablemente importado en bruto o semielaborado, junto a bloques destinados a decoración arquitectónica que debieron ser trabajados por artesanos establecidos en Tarraco. En el caso de los soportes epigráficos, tanto las inscripciones edilicias como los restantes monumentos honoríficos fueron realizados en la ciudad, como corroboran las similitudes paleográficas con respecto a la producción de soportes epigráficos realizados en piedra caliza local (cf. p.e. Peña Jurado et alii, 2015: 186-187, figura 4), utilizada en masa para estos fines a partir del periodo flavio.

\section{CONSIDERACIONES FINALES}

En definitiva, si el mármol lunense tuvo un rol fundamental en los programas arquitectónicos y decorativos en las ciudades del Occidente romano, esta afirmación es especialmente válida en una urbe que había de emular en el ámbito provincial la imagen de Roma, como capital de la provincia más extensa de Hispania y del Imperio. Su elección estuvo repleta de significado ideológico y propagandístico, como demuestra su empleo claramente limitado a las inscripciones más relevantes de los lugares más representativos 
de la celebración imperial en la ciudad. El más solemne de ellos, el temenos o porticado de la plaza que rodeaba al templo dedicado al divus Augustus, ha proporcionado las evidencias más significativas. Entre ellos se encuentran fragmentos que han sido relacionados con miembros de la dinastía flavia, pero destaca una inscripción que alude al mismo templo y que pudiera tratarse del homenaje a una figura emblemática dedicada al culto imperial, si bien el estado tan fragmentado en el que se encuentra impide saber a quién conmemoraba.

En el periodo de mayor auge de la ciudad y del propio Imperio, las evidencias se concentran en el foro provincial, mientras que el número predominante de inscripciones realizadas mediante placados de mármoles blancos en otros edificios, como el foro o el teatro, se datan ya en la época severiana. En este periodo el concilium provinciae Hispaniae citerioris se encontraba en un claro retroceso, como manifiesta la irregularidad de los homenajes a flamines a partir de finales del siglo II d. C., materializada asimismo en la ruptura de la uniformidad de los soportes epigráficos (Alföldy, 1979: 233-234 = Gorostidi Pi (ed.), 2017: 100-101 (G. Alföldy); Alföldy, 2012: 446-449 = Gorostidi Pi (ed.), 2017: 357-359 (G. Alföldy). Ello nos induce a pensar que en Tarraco, cuando el Imperio no había mostrado aún síntomas de crisis, este material estuvo estrictamente restringido a la cúpula del poder imperial y a la administración provincial. Únicamente a partir de finales del siglo II d. C. y con la decadencia de las ciudades y sus élites, su empleo debió extenderse a espacios de administración local, lo que también nos lleva a preguntarnos sobre el origen del material en este periodo. Creemos posible formular la hipótesis de que proceda de material en bruto o semielaborado que se encontraba en stock, quizá como excedente de la producción del foro provincial. En favor de esta suposición está el hecho de que, si bien se usa a finales del siglo II e inicios del III ya en espacios administrados por el ordo decurionum, el mármol no dejó de estar restringido a homenajes imperiales de gran entidad.

\section{BIBLIOGRAFÍA}

Alföldy, G. (1973), Flamines provinciae Hispaniae citerioris (Anejos de Archivo Español de Arqueología, VI), Madrid, Consejo Superior de Investigaciones Científicas.

Alföldy, G. (1979), "Bildprogramme in den Städten des Conventus Tarraconensis - Das Zeugnis der Statuenpostamente", Revista de la Universidad Complutense, 18, pp. 187-200.

- (2012a), "Officina lapidaria Tarraconensis", en A. Donati y G. Poma (eds.), L'officina epigrafica romana. In ricordo di Giancarlo Susini (Epigrafia e antichità, 30), Faenza, Lega, pp. 429-471.

- (2012b), Las inscripciones monumentales del anfiteatro de Tarraco (Tarraco Archaeologica, 2), Tarragona, Reial Societat Arqueològica Tarraconense.

Àlvarez Pérez, A., García-Entero, V., Gutiérrez Garcia, A. y Rodà de Llanza, I. (2009), El marmor de Tarraco. Explotació, utilització i comercialització de la pedra de Santa Tecla en època romana. Tarraco marmor. The Quarrying, Use and Trade of Santa Tecla Stone in Roman Times (Hic et Nunc, 6), Tarragona, Institut Català d'Arqueologia Clàssica.

Andreu Pintado, J. (2004a), Edictum, Municipium y Lex: Hispania en época flavia (69-96 d. C.), Oxford, Archaeopress.

Andreu Pintado, J. (2004b), "Construcción pública y municipalización en la provincia Hispania Citerior: la época flavia", Iberia, 1, pp. 39-75.

Andreu Pintado, J. (2012), "Los marmora de Lusitania: su uso como soporte epigráfico", en V. García-Entero (ed.), El marmor en Hispania. Explotación, uso y difusión en época romana. Marmor in Hispania: exploitation, use and diffusion in Roman times, Madrid, Universidad Nacional de Educación a Distancia, pp. 315-330.

Aranda González, R. y Ruiz, J. C. (2019), "El fenómeno de la reutilización en la necrópolis 
paleocristiana: algunos casos concretos y primeras reflexiones", en J. López Vilar (ed.), Tarraco Biennal. Actes $4 t$ Congrés Internacional d'Arqueologia i Món Antic. VII Reunió d'Arqueologia Cristiana Hispànica. El cristianisme en l'Antiguitat Tardana: Noves perspectives. Tarragona, 21-24 de novembre de 2018, Tarragona: URV/IEC, pp. 91-97.

CIL II²/14 = Alföldy, G. (2011-2016), Corpus Inscriptionum Latinarum. Inscriptiones Hispaniae Latinae, editio altera. Pars XIV, conventus Tarraconensis pars meridionalis. Fasc. 2-4, Colonia Iulia Urbs Triumphalis Tarraco, Berlin/New York, De Gruyter.

Díaz García, M. y Teixell, I. (2014), "La plaza de representación del Concilium Provinciae Hispaniae Citerioris: soluciones y dudas sobre su interpretación arquitectónica", en J. M. Álvarez Martínez, T. Nogales Basarrate e I. Rodà de Llanza (eds.), Actas XVIII Congreso Internacional de Arqueología Clásica. Centro y Periferia en el Mundo Clásico $=$ Proceedings of the 18th International Congress of Classical Archaeology. Centre and Periphery in the Ancient World II, Museo Nacional de Arte Romano, Mérida, pp. 837841.

Fishwick, D. (2002), The Imperial Cult in the Latin West. Studies in the Ruler Cult of the Western Provinces of the Roman Empire. III: Provincial Cult. Part 2: The Provincial Priesthood, Leiden / Boston / Köln, Brill.

Fortuny Mendo, K. y Ruiz, J. C. (en prensa), "El conjunto tardoantiguo de la Plaza d'en Rovellat de Tarragona: del análisis arquitectónico al estudio de los elementos marmóreos altoimperiales hallados en contexto secundario", en Exemplum et Spolia. La reutilización arquitectónica en la transformación del paisaje urbano en las ciudades históricas, en prensa.

Galán Palomares, L. (2019), "Los soportes hermaicos en Hispania: estudio sobre la funcionalidad y dispersión de los hermae epigráficos en la península ibérica", Revista d'Arqueologia de Ponent, 29, pp. 69-89.

Gorostidi Pi, D. (2017), "Memoria, prestigio y monumento: los pedestales de los viri flaminales en Tarraco y su difusión en ámbito provincial", en A. Ruiz e J. M. Iglesias (eds.), Monumenta et Memoria. Estudios de Epigrafía Romana, Roma, «L'Erma» di Bretschneider, pp. 167-187.

Gorostidi Pi, D. (ed.) (2017), Géza Alföldy. Estudios tarraconenses, Tarragona, Universitat Rovira i Virgili/Institut Català d'Arqueologia Clàssica.

Gorostidi Pi, D. y López Vilar, J. (2015), "La officina lapidaria tarraconense en época augustal: actualización del corpus y primeras consideraciones", en J. López Vilar (ed.), Tarraco Biennal. Actes 2on Congrés Internacional d'Arqueologia i Món Antic August i les províncies occidentals. 2000 aniversari de la mort d'August (2014), Tarragona, Vol. 2., pp. 257-262.

Gorostidi Pi, D. y Ruiz, J. C. (2017a), "The Flavian officina lapidaria Tarraconense: colour and texture in the service of Rome", Studia Europaea Gnesnensia, 16, pp. 319-350.

Gorostidi Pi, D. y Ruiz, J. C. (2017b), "La inscripción monumental del circo de Tarraco: primera hipótesis reconstructiva”, en J. López Vilar (ed.), Tarraco Biennal. Actes 3r Congrés Internacional d'Arqueologia i Món Antic. La glòria del circ: curses de carros i competicions circenses. In memoriam Xavier Dupré i Raventós. Tarragona, 16-19 de novembre de 2016, Tarragona, Fundació Privada Mútua Catalana, pp. 279-286.

Gorostidi Pi., López Vilar, J. y Gutiérrez García-Moreno, A. (2018), “The Use of Alcover Stone in Roman Times (Tarraco, Hispania Citerior). Contributions to the the Officina Lapidaria Tarraconensis", en D. Matetić y K. Marasović (eds.), ASMOSIA XI. Interdisciplinary Studies of Ancient Stone. Proceedings of the Eleventh International Conference of ASMOSIA, Split, 18-22 May 2015, Split, Arts Academy in Split, pp. 577-582. 
Gutiérrez García-Moreno, A. (2009), Roman Quarries in the Northeast of Hispania (Modern Catalonia) (Documenta 10), Tarragona, Institut Català d'Arqueologia Clàssica.

Gutiérrez García-Moreno, A. y Rodà de Llanza, I. (2012). "El mármol de Luni-Carrara en la fachada mediterránea de Hispania", en S. Keay (ed.), Rome, Portus and the Mediterranean (Archaeological Monographs, 21), London, British School at Rome, pp. 293-312.

Macias i Solé, J. M., Muñoz Melgar, A., Peña Jurado, A. y Teixell, I. (2014a), "El templo de Augusto en Tarraco: Últimas excavaciones y hallazgos", en J. M. Álvarez Martínez, T. Nogales Basarrate e I. Rodà de Llanza (eds.), Actas XVIII Congreso Internacional de Arqueología Clásica. Centro y Periferia en el Mundo Clásico = Proceedings of the 18th International Congress of Classical Archaeology. Centre and Periphery in the Ancient World II, Museo Nacional de Arte Romano, Mérida, pp. 1539-1543.

Macias i Solé, J. M., Puche Fontanilles, J. M., Toldrà, J. M. y de Solà Morales, P. (2014b), "Reconstrucción digital del Anfiteatro romano de Tarraco (Hispania Tarraconensis) mediante escàner laser. Bases para el estudio analítico y estructural”, en J. M. Álvarez Martínez, T. Nogales Basarrate e I. Rodà de Llanza (eds.), Actas XVIII Congreso Internacional de Arqueología Clásica. Centro y Periferia en el Mundo Clásico = Proceedings of the 18th International Congress of Classical Archaeology. Centre and Periphery in the Ancient World II, Museo Nacional de Arte Romano, Mérida, pp. 87-90.

Macias i Solé, J. M., Fiz, I., Piñol, Ll., Miró i Alaix, M. T. y Guitart, J. (dirs.) (2007), Planimetria Arqueològica de Tàrraco (Atles d'Arqueologia Urbana de Catalunya, 2/ Treballs d'Arqueologia Urbana, 1/Documenta, 5), Tarragona, Departament de Cultura i Mitjans de la Comunicació de la Generalitat de Catalunya/Ajuntament de Tarragona. Conselleria de Patrimoni/Institut Català d'Arqueologia Clàssica.

Mar Medina, R. y Pensabene, P. (2009), "Financiación de la edilicia pública y cálculo de los costes del material lapídeo: el caso del foro superior de Tárraco", Butlletí Arqueològic, 31, pp. 345-409.

Mar Medina, R., Ruiz de Arbulo Bayona, J., Vivó i Codina, D., Beltrán Caballero, J. A. y Gris Jeremias, F. (2015), Tarraco. Arquitectura y urbanismo de una capital provincial romana, II: La ciudad imperial (Documents d'Arqueologia Clàssica, 6), Tarragona, Universitat Rovira i Virgili.

Miró i Alaix, M. T. (2017), "El circ, un edifici d'espectacles com a element vertebrador de l'urbanisme de Tàrraco: 35 anys de recerques", en J. López (ed.), Tarraco Biennal. Actes 3r Congrés Internacional d'Arqueologia i Món Antic. La glòria del circ: curses de carros i competicions circenses. In memoriam Xavier Dupré i Raventós. Tarragona, 16-19 de novembre de 2016, Tarragona, Fundació Privada Mútua Catalana, pp. 219230.

Ortiz de Urbina, E. (2006), "La exaltación de la élite provincial. Los homenajes estatuarios decretados o autorizados por la provincia Hispania Citerior", Epigraphica, 68, pp. 4584.

Pensabene, P. (1993), "La decorazione architettonica dei monumenti provinciali di Tarraco", en R. Mar Medina (ed.), Els monuments provincials de Tarraco. Noves aportacions al seu coneixement (Documents d'Arqueologia Clàssica, 1), Tarragona, Universitat Rovira i Virgili, pp. 25-105.

Pensabene, P. (2012), "Il marmo lunense nei programmi architettonici e statuari dell'Occidente romano", en V. García-Entero (ed.), El marmor en Hispania: explotación, uso y difusión en época romana - Marmor in Hispania: exploitation, use and diffusion in Roman times, Madrid, Universidad Nacional de Educación a Distancia, pp. 17-47.

Pensabene, P. y Domingo Magaña, J. Á. (2019), "El Concilium Provinciae Hispaniae 
Citerioris (CPHC): una lectura arquitectónica a la luz de los nuevos datos y de los conjuntos imperiales de Roma", Butlletí Arqueològic, V, 41, pp. 41-126.

Pensabene, P. y Mar Medina, R. (2010), "Il tempio di Augusto a Tarraco. Gigantismo e marmo lunense nei luoghi di culto imperiale in Hispania e Gallia", Archeologia Classica, LXI, pp. 243-307.

Peña Jurado, A., Gorostidi Pi, D., Macias i Solé, J.M., Muñoz Melgar, A., Rodà de Llanza, I. y Teixell, I. (2015), "Más datos sobre el templo del Divus Augustus de Tarraco: a propósito de una nueva inscripción", en J. López (ed.), Tarraco Biennal. Actes 2on Congrés Internacional d'Arqueologia i Món Antic. August i les províncies occidentals. 2000 aniversari de la mort d'August (Tarragona, del 26 al 29 de novembre de 2014), Tarragona, Fundació Privada Mútua Catalana, pp. 181-189.

- (2017), "Materiales lapídeos locales e importados en los programas epigráficos oficiales de Tarraco hasta la época julio-claudia", Anales de Arqueología Cordobesa, 28, pp. 33-62.

- (2018), "La temprana importación de mármoles blancos en Tarraco", Pyrenae, 49.1, pp. 99-123.

- (2019a), "Marmora foráneos en Tarraco a comienzos de la época imperial", en P. Aranda, M. García, A. Sierra y G. de Tord (eds.), Respuestas al cambio en la Prehistoria y el Mundo Antiguo, Zaragoza, Prensas de la Universidad de Zaragoza, pp. 76-92.

- (2019b), "El ambiente epigráfico del foro 'colonial' de Tarraco durante las épocas augustea y julio-claudia", Lucentum, 38, pp. 301-320.

- (en prensa), "Nuevos relieves arquitectónicos con decoración vegetal procedentes del área del templo al divus Augustus en Tarraco", en A. Gutiérrez García-Moreno y D. Gorostidi Pi (eds.), Barcino-Tarraco-Roma. Poder y prestigio en mármol. Homenaje a Isabel Rodà de Llanza, en prensa.

Rodríguez Ceballos, M. y Salido, J. (2014), "Marmora para las elites de Clunia: el empleo del Espejón como soporte epigráfico y nuevas evidencias de su uso ornamental", en A. Caballos Rufino y E. Melchor Gil (eds.), De Roma a las provincias: las elites como instrumento de proyección de Roma. Juan Francisco Rodríguez Neila in honorem, Sevilla / Córdoba, Universidad de Sevilla / Universidad de Córdoba, pp. 632-668.

Ruiz, J. C. y Aranda González, R. (en prensa), "La reutilización de elementos ornamentales y epigráficos de ámbitos públicos altoimperiales en la necropolis paleocristiana de Tarragona", en $19^{\text {th }}$ International Congress of Classical Archaeology. Cologne/Bonn, 22 - 26 May 2018, en prensa.

Ruiz, J. C., Lapuente Mercadal, P., Gorostidi Pi, D. y Brilli, M. (en prensa), "Marble Fragments of Monumental Inscriptions from the Tarraco Circus (Hispania citerior)", en ASMOSIA $X I I I$, en prensa.

Soler Huertas, B. (2005), "El travertino rojo de Mula (Murcia). Definición de un mármol local", Verdolay, 9, pp. 141-164. 